\title{
PERANAN TATA GUNA LAHAN BAGIAN HULU TERHADAP KESUBURAN PERAIRAN PADA WADUK JATIBARANG, SEMARANG
}

\author{
Role of Land Use Upstream Part of Productivity Water Level at Jatibarang Reservoir, Semarang \\ Yohana T. E. Silitonga, Bambang Sulardiono*), Pujiono Wahyu Purnomo \\ Program Studi Manajemen Sumberdaya Perairan \\ Departemen Sumberdaya Akuatik Fakultas Perikanan dan Ilmu Kelautan, Universitas Diponegoro \\ J1. Prof. Soedharto, SH, Tembalang, Semarang, Jawa Tengah-50275 \\ Emil : yohanatioelizabethsilitonga@gmail.com
}

\begin{abstract}
ABSTRAK
Kota Semarang dikenal sebagai kota yang sering mengalami banjir. Pembangunan Waduk Jatibarang merupakan salah satu cara untuk mengatasi permasalahan banjir di kota Semarang. Tata guna lahan adalah sebuah pemanfaatan lahan dan penataan lahan yang dilakukan sesuai dengan kondisi eksisting alam. Kegiatan manusia dan penggunaan kawasan yang tidak terkendali memberikan pengaruh negatif yang berpotensi menyumbang limbah rumah tangga dan mempengaruhi tingkat kesuburan perairan Waduk Jatibarang. Tujuan penelitian ini adalah untuk mengidentifikasi tata guna lahan bagian hulu di sekitar Waduk Jatibarang dan mengetahui tingkat kesuburan perairan Waduk Jatibarang. Metode yang digunakan adalah metode survey. Penelitian dilaksanakan pada tanggal 15 - 27 September 2017. Penelitian ini dilakukan pada 6 titik sampling di Waduk Jatibarang. Hasil penelitian menunjukkan bahwa lahan bagian hulu Waduk Jatibarang terdiri dari $50 \%$ vegetasi, 20\% pemukiman, 25\% persawahan,dan 5\% tegalan. Karakter fisika dan kimia perairan Waduk Jatibarang tergolong baik. Kandungan DO antara 4,80 - 6,96 mg/l, kandungan nitrat antara 0,64 - 1,10 ppm, total fosfat antara 0,13 - 0,26 ppm, dan klorofil-a antara 2,72 - 4,29 ppm. Indeks TSI Carlson berkisar antara 52,57 - 55,36 menunjukkan status kesuburan perairan eutrofik ringan.
\end{abstract}

Kata Kunci: Tata Guna Lahan; Kesuburan Perairan; Waduk Jatibarang

\begin{abstract}
Semarang City is known as flooded city. Construction of Jatibarang Reservoir is a solution to solve the flood problem in Semarang city. Land use is a utilization land and land arrangement in accordance of the nature existantion condition. Human activities nearby the waters can lead to the entry of various substances into the aquatic system. Uncontrolled use of the area has a negative effect that potentially contributes to household waste and affect the water thropic level. The purpose of this study is to identify the upstream of land use in Jatibarang Reservoir and to know Water Thropic State at Jatibarang Reservoir. Research reference is using survey method. The research was conducted on 15 - 27 September 2017. This research was conducted on six sampling points, the scope of land studied by upstream area in Jatibarang Reservoir with percentage of 50\% vegetation, 20\% settlement, 25\% rice field, and 5\% moor. Physical and chemical character of Waters of Jatibarang Reservoir are good. DO content between 4,80 - 6,96 mg / l, nitrate content between 0,64 - 1,10 ppm, total phosphate between 0,1305 - 0,2695 ppm, and chlorophyll-a between 2,72-4,29 ppm. The Carlson TSI index ranged from 52,57 to 55,93 indicates the mild eutrophic water thropic state.
\end{abstract}

Keywords : Land Use; Productivity Water; Jatibarang Reservoir

*) Penulis penanggungjawab

\section{PENDAHULUAN}

Kota Semarang merupakan kota yang strategis sebagai penghubung antara Jawa bagian Barat dan Jawa bagian Timur. Kota Semarang juga dikenal dengan kota yang sering mengalami banjir. Banjir yang dialami oleh kota Semarang disebabkan oleh ketidaksesuaian pemanfaatan lahan yang memicu tingkat sedimentasi yang tinggi. Sedimentasi yang tinggi menyebabkan volume daerah tampungan air yang awalnya banyak menjadi berkurang karena daerah penampungan air semakin banyak diisi oleh sedimen yang dibawa air dari hulu.

Tata guna lahan menurut Vink (1975) dalam Widayanti (2010) adalah setiap bentuk intervensi manusia terhadap lahan yang dapat berfungsi untuk memenuhi kebutuhannya sendiri baik material ataupun spiritual. Seperti halnya pembangunan Waduk Jatibarang juga mendapat intervensi dari manusia. Pembangunan Waduk

\footnotetext{
${ }^{\odot}$ Copyright by Management of Aquatic Resources (MAQUARES)
} 
Jatibarang juga tentu mendapat intervensi dari manusia yang berada disekitar Waduk Jatibarang baik pengelola waduk maupun warga sekitar untuk dapat memenuhi kebutuhan sehari - hari mereka, misalnya membuat daerah wisata, tempat pembudidayaan ikan air tawar, tempat pembuangan akhir (TPA).

Kegiatan manusia di sekitar perairan dapat mengakibatkan masuknya bermacam substansi ke dalam sistem perairan. Sebagian dari substansi ini secara tidak langsung tidak berbahaya, namun dapat mempengaruhi keseimbangan ekosistem dan tingkat kesuburan di perairan tersebut. Untuk mengetahui tingkat kesuburan perairan, salah satu caranya adalah dengan melakukan pengukuran produktivitas primer dalam perairan. Tingkat kesuburan perairan dapat dilihat dari tingkat nutrisi yang dibutuhkan oleh organisme produsen dalam perairan tersebut. Produktivitas primer fitoplankton menggambarkan masukan terbesar materi organik baru ke perairan, menunjukkan tersedianya nutrisi untuk pertumbuhan fitoplankton (Wetzel, 2001 dalam Hardiyanto et al., 2012).

Berdasarkan uraian diatas, penelitian ini diharapkan dapat memberi informasi mengenai kesuburan perairan serta hubungan tata guna lahan dengan kesuburan perairan di hulu Waduk Jatibarang. Karena kesuburan perairan yang baik diperoleh dari penataan lahan yang baik. Apalagi dilokasi tersebut terdapat pembudidayaan ikan air tawar, agar ikan yang dibudidayakan tetap sehat maka diperlukan kondisi perairan yang sehat yang salah satunya adalah dengan menjaga kesuburan perairan.

Tujuan penelitian ini adalah untuk mengidentifikasi tata guna lahan bagian hulu Waduk Jatibarang dan untuk mengetahui kesuburan perairan di beberapa lokasi dalam Waduk Jatibarang.

\section{MATERI DAN METODE PENELITIAN}

Materi penelitian yang dilakukan di Waduk Jatibarang Semarang ini adalah pengamatan terhadap tata guna lahan dan pengaruhnya terhadap kesuburan perairan pada parairan waduk tersebut. Metode yang digunakan untuk mengidentifikasi penggunaan lahan menggunakan data Digital Elevation Model Semarang 2011. Pengambilan sampel dilakukan di 6 titik pengambilan sampling pada koordinat $7^{\circ} 02^{\prime} 42^{\prime \prime} \mathrm{S}$ dan $110^{\circ} 20^{\prime} 52^{\prime \prime} \mathrm{T}$ sebagia titik $1 ; 7^{\circ} 02^{\prime} 20^{\prime \prime S}$ dan $110^{\circ} 20^{\prime} 54^{\prime \prime T}$ sebagai titik $2 ; 7^{\circ} 02 ' 26^{\prime \prime S}$ dan $110^{\circ} 20^{\prime} 39^{\prime \prime T}$ sebagai titik $3 ; 7^{\circ} 02^{\prime} 27^{\prime \prime S}$ dan $110^{\circ} 20^{\prime} 45^{\prime \prime T}$ sebagai titik 4 ; $^{\circ} 02^{\prime} 31^{\prime \prime S}$ dan 110²0'49"T sebagai titik 5; dan $7^{\circ} 02^{\prime} 29^{\prime \prime S}$ dan $110^{\circ} 20^{\prime} 58^{\prime \prime T}$ sebagai titik 6. Pengambilan air sampel mengunakan metode purposive sampling, yaitu teknik penentuan sampel dengan pertimbangan tertentu. Penentuan titik sampling ditentukan berdasarkan penelusuran yang telah dilakukan di bagian hulu Waduk Jatibarang Semarang. Hal ini diperkuat oleh Poppo et al (2012), bahwa metode purposive sampling yaitu penentuan stasiun pengamatan dilakukan dengan memperhatikan berbagai pertimbangan dan kondisi daerah penelitian yang sudah diketahui sebelumnya. Berikut adalah gambaran lokasi penelitian beserta titik pengambilan sampel yang ditunjukkan oleh Gambar 1.

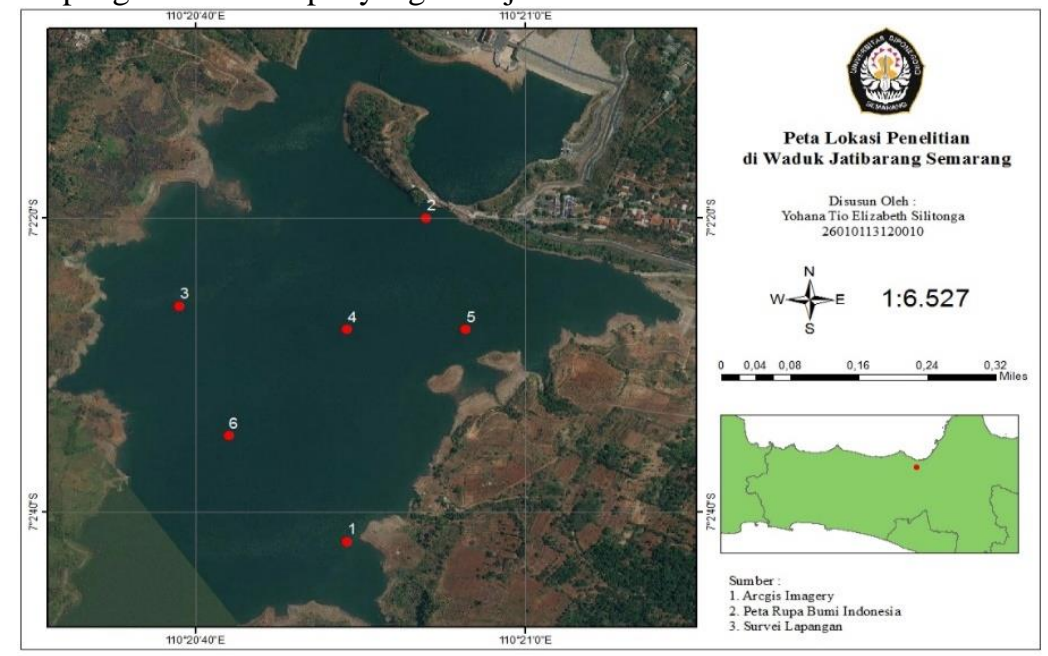

Gambar 1. Peta Lokasi Sampling

Untuk menentukan tingkat kesuburan perairan Waduk Jatibarang menggunakan metode TSI Carlson (1977) dalam Susanti et al (2012) yaitu menentukan indeks TSI menggunakan data kedalaman sechi disk, total fosfat, dan klorofil-a dengan rumus sebagai berikut:

TSI TP $=14,42 \times \operatorname{Ln}(\mathrm{TP})+4,15(\mu \mathrm{g} / 1)$

TSI CA $=30,6+9,81 \times$ Ln [Klor-a] $(\mu \mathrm{g} / \mathrm{l})$

TSI $-\mathrm{SD}=60-14,41 \times \mathrm{Ln}[\mathrm{Secchi}]($ meter $)$

Rata-rata TSI $=($ TSI-P + TSI-Kla + TSI-SD $) / 3$

Dimana :

TSI -TP : nilai indeks kesuburan untuk total fosfat

TSI -Kla : Nilai indeks kesuburan untuk klorofil a dan

TSI - SD : Nilai indeks kesuburan untuk kedalaman Secchi Disk 


\section{HASIL DAN PEMBAHASAN}

Sesuai dengan tujuan penelitian maka penelitian dilakukan identifikasi terhadap tata guna lahan. Berikut adalah gambaran penataan tata guna lahan di bagian hulu Waduk Jatibarang.

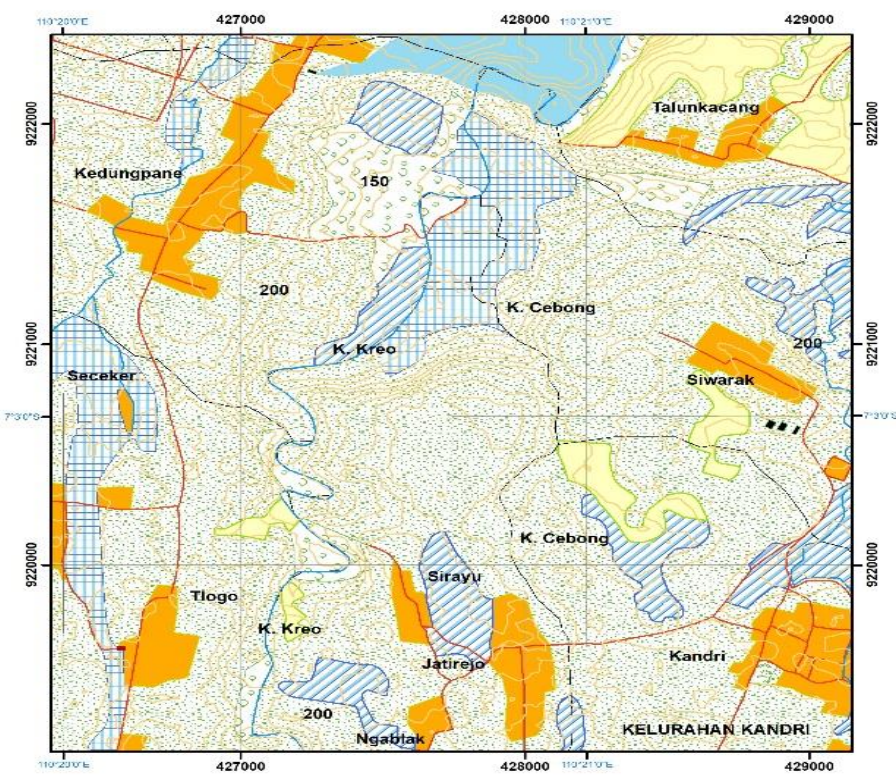

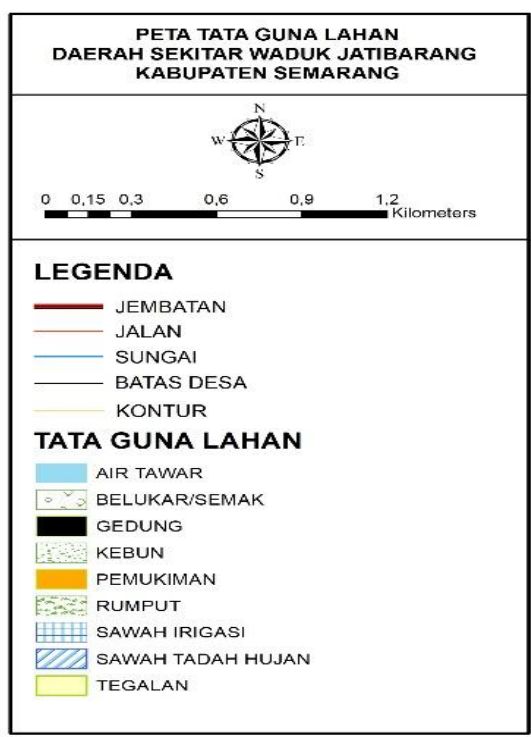

Sumber: Digital Elevation Model Semarang, 2011

Gambar 2. Peta Tata Guna Lahan

Pada gambar diatas dapat diperhatikan bahwa kondisi lahan Waduk Jatibarang berupa 50\% dipenuhi oleh vegetasi, untuk pemukiman sekitar 20\%, untuk persawahan 25\%, dan 5\% untuk tegalan. Berdasarkan Gambar 2 menunujukkan tata guna lahan pada kawasan hulu Waduk Jatibarang masih tergolong relatif alami.

\section{Kualitas Perairan}

Sebaran temperatur pada lokasi penelitian dapat dilihat pada Gambar 3. Temperatur pada Waduk Jatibarang berkisaran antara $30-31{ }^{\circ} \mathrm{C}$ dengan temperatur paling tinggi berada di titik 1 yaitu 31 derajat celcius dan pada yang lain memiliki temperatur yang merata yaitu 30,5 derajat celcius.
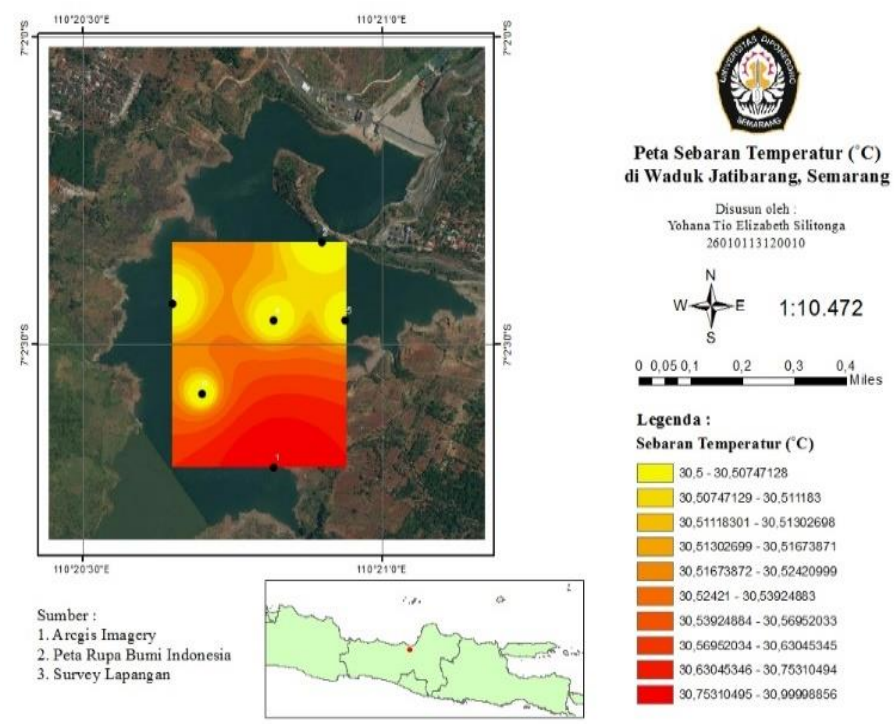

Gambar 3. Peta Sebaran Temperatur

Sebaran kecerahan yang diperoleh selama penelitian ditunjukkan pada Gambar 4. Kecerahan perairan berkisar antara 32 - $43 \mathrm{~cm}$ dengan tingkat kecerahan perairan paling tinggi berada pada titik 2, 3 dan tingkat kecerahan paling rendah berada pada titik 1 .

\footnotetext{
${ }^{\circ}$ Copyright by Management of Aquatic Resources (MAQUARES)
} 

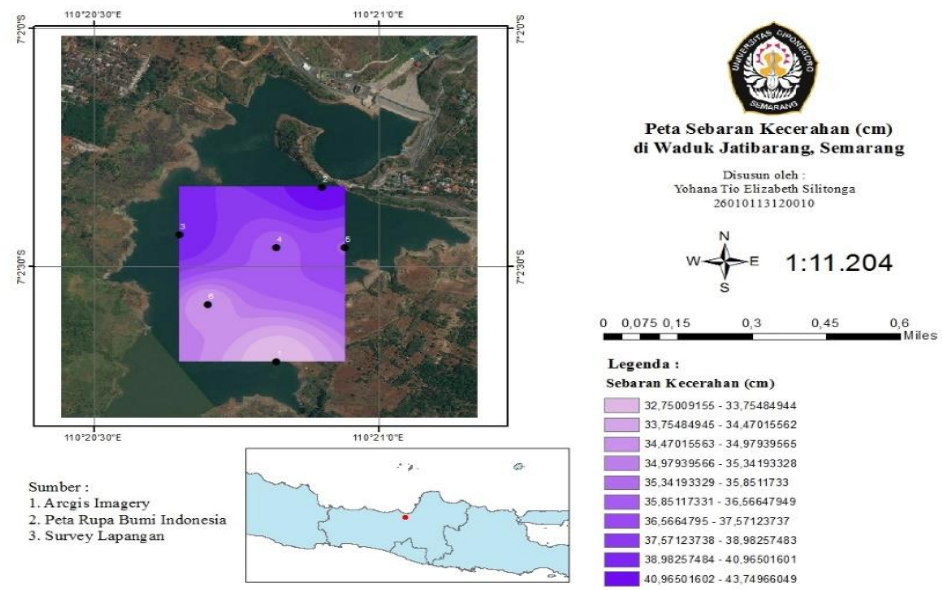

Gambar 4. Peta Sebaran Kecerahan

Sebaran kecepatan arus ditunjukkan pada Gambar 5. Berdasarkan Gambar 5 menunjukkan bahwa kecepatan arus paling tinggi pada titik 6 degredasi warna paling mencolok dan kecepatan arus paling rendah pada titik 1, 2, dan 4 yang memiliki degredasi warna hampir sama dengan. Rata - rata kecepatan arus berkisar antara $0,01-0,1 \mathrm{~m} / \mathrm{s}$.

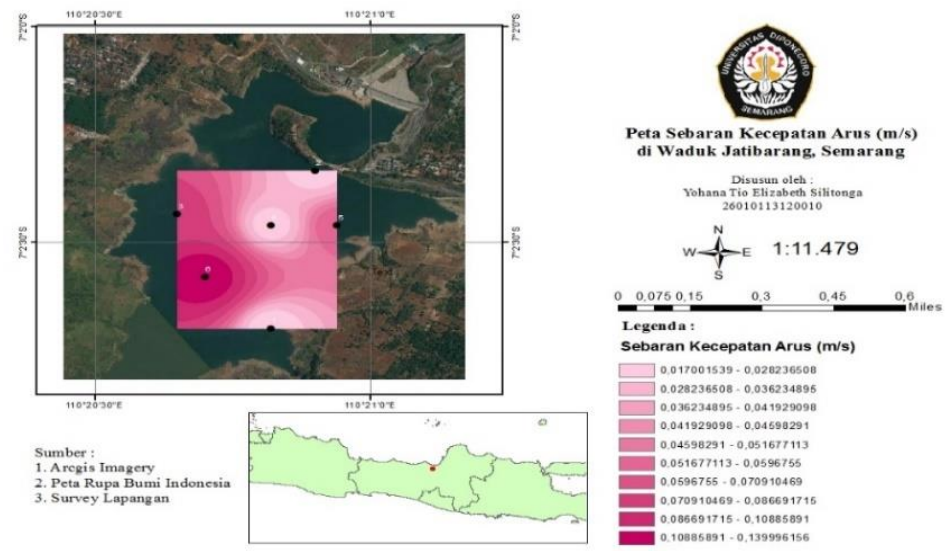

Gambar 5. Peta Sebaran Kecepatan Arus

Sebaran pH pada Waduk Jatibarang ditunjukkan pada Gambar 6. Berdasarkan Gambar 6 diatas menunjukkan bahwa pada empat titik sampling memiliki pH lebih tinggi, yaitu pada titik 3, 4, 5, dan 6 sedangkan $\mathrm{pH}$ terendah berada pada titik 1 dan 2. Tingkat $\mathrm{pH}$ pada Waduk Jatibarang menunjukkan memiliki kisaran rata - rata antara 7,5 - 8 .
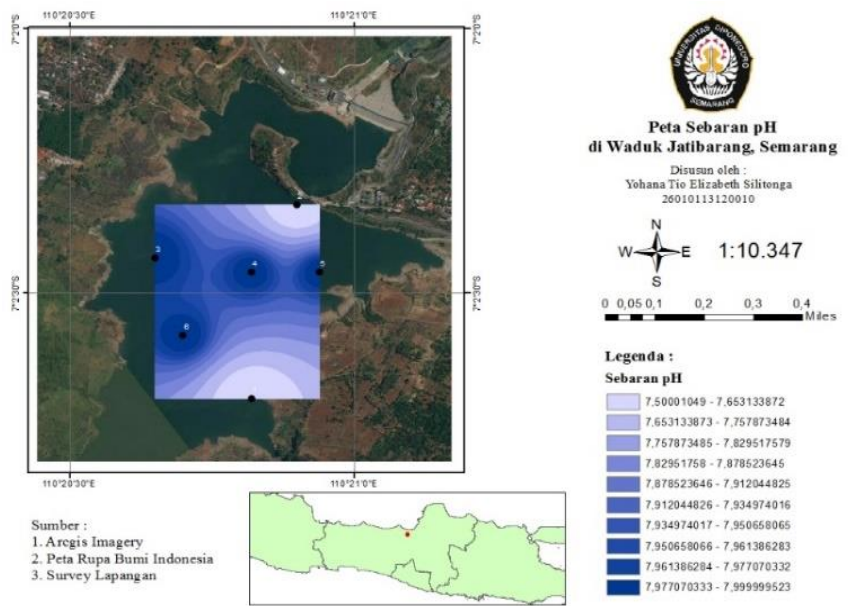

Gambar 6. Peta Sebaran $\mathrm{pH}$

Sebaran DO pada Waduk Jatibarang ditunjukkan pada Gambar 7. Berdasarkan Gambar 7 menunjukkan bagian yang berwarna biru memiliki kandungan DO yang rendah dan titik yang memiliki kandungan DO yang rendah berada pada titik 1, 2, dan 3 sedangkan yang menunjukkan kandungan DO yang tinggi berwarna merah

${ }^{\oplus}$ Copyright by Management of Aquatic Resources (MAQUARES) 
dan titik yang memiliki kandungan DO yang paling tinggi pada titik 5. Rata - rata DO pada Waduk Jatibarang berkisar antara $4,8-6,9 \mathrm{mg} / \mathrm{l}$.
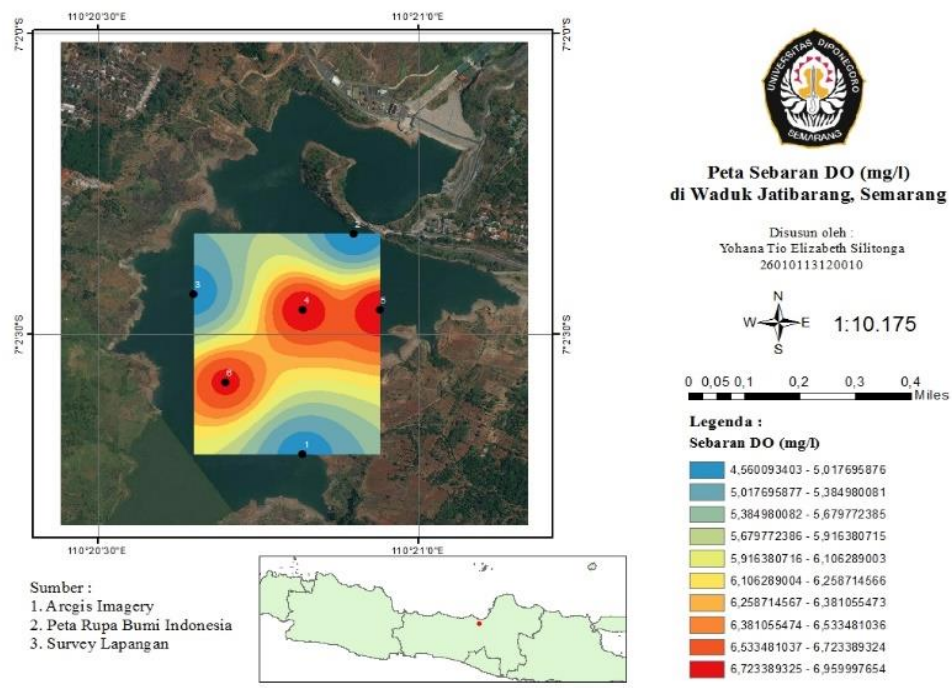

Gambar 7. Peta Sebaran DO

Sebaran TSS pada Waduk Jatibarang ditunjukkan pada Gambar 8. Berdasarkan peta sebaran TSS nilai tertinggi memiliki warna coklat dan titik yang memiliki nilai TSS tertinggi berada pada titik 6 sedangkan nilai TSS terendah ditunjukkan dengan warna kuning yang berada pada titik 1. Rata - rata nilai TSS pada Waduk Jatibrang berkisar antara $60-130 \mathrm{mg} / \mathrm{l}$.

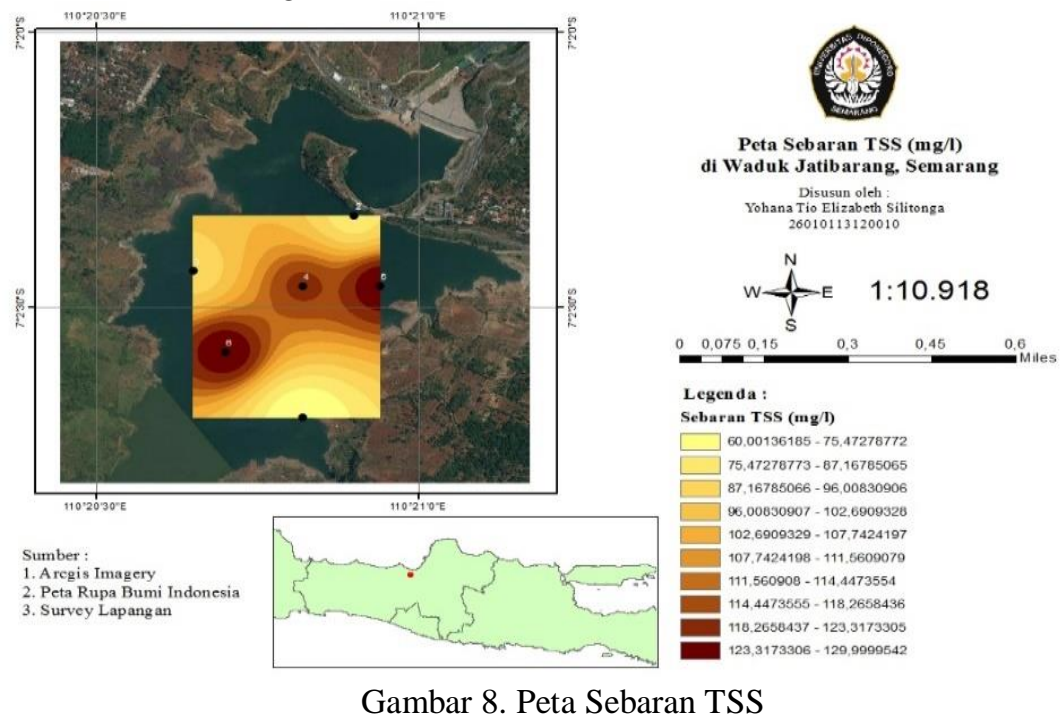

Sebaran TDS ditunjukkan pada Gambar 9. Berdasarkan peta sebaran tersebut menunjukkan bahwa nilai TDS terendah diberi warna coklat dan titik sampling yang memiliki nilai TDS terendah pada titik 4 sementara hijau tua menunjukkan nilai TDS yang tinggi dan berada pada titik 2. Rata - rata nilai TDS pada Waduk Jatibarang berkisar antara $245-360 \mathrm{mg} / \mathrm{l}$. 

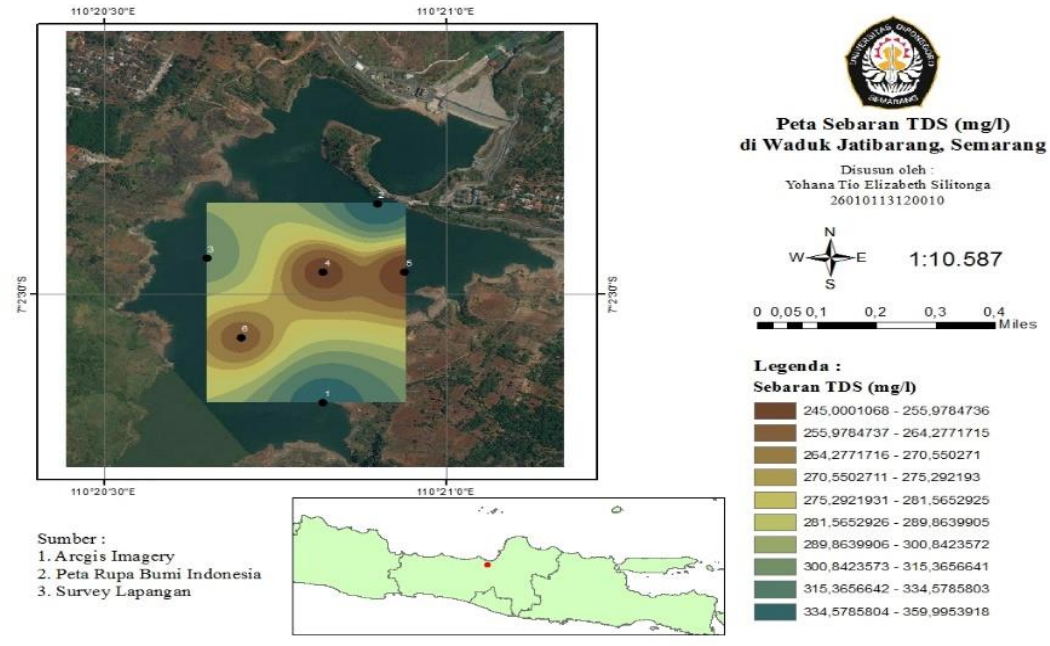

Gambar 9. Peta Sebaran TDS

Nitrat merupakan salah satu variabel utama yang menentukan kesuburan perairan. Hasil yang diperoleh selama penelitian dapat ditunjukkan pada Tabel 1

Tabel 1. Hasil Pengukuran Nitrat

\begin{tabular}{cccc}
\hline \multirow{2}{*}{ Titik } & \multicolumn{2}{c}{ Kandungan Nitrat (ppm) } & \multirow{2}{*}{ Rata-rata } \\
\cline { 2 - 3 } & 15 September 2017 & 27 September 2017 & 1,106 \\
1 & 0,962 & 1,25 & 0,6415 \\
2 & 0,866 & 0,417 & 0,8495 \\
3 & 1,122 & 0,577 & 0,7215 \\
4 & 0,609 & 0,834 & 1,01 \\
5 & 1,443 & 0,577 & 1,042 \\
6 & 0,93 & 1,154 & \\
\hline
\end{tabular}

Berdasarkan data tersebut menunjukkan rata - rata kadar nitrat tergolong baik. Rata - rata kadar total fosfat berkisar antara 0,6 - 1,1 ppm. Menurut Basmi (2000), pertumbuhan optimal fitoplankton jika kandungan nitrat di perairan 3,9-15,5 ppm. Berdasarakan hasil diatas perairan tergolong eutrofik ringan. Sebaran nitrat pada Waduk Jatibarang ditunjukkan pada Gambar 10.
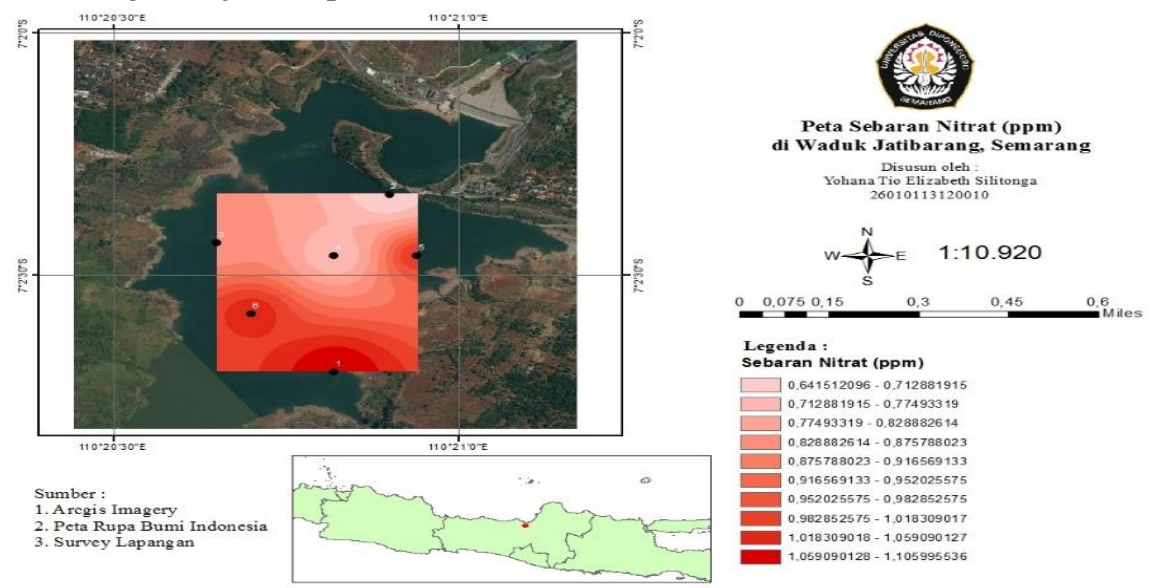

Gambar 10. Peta Sebaran Nitrat

Total fosfat juga merupakan variabel utama yang dapat menentukan kesuburan perairan. Hasil yang diperoleh selama penelitian ditunjukkan pada Tabel 2.

Tabel 2. Hasil Pengukuran Total Fosfat

\begin{tabular}{cccc}
\hline \multirow{2}{*}{ Titik } & \multicolumn{2}{c}{ Total Fosfat (ppm) } & \multirow{2}{*}{ Rata-rata } \\
\cline { 2 - 3 } & 15 September 2017 & 27 Septemebr 2017 & 0,237 \\
2 & 0,2 & 0,275 & 0,269 \\
3 & 0,275 & 0,264 & 0,213 \\
4 & 0,2 & 0,226 & 0,189 \\
5 & 0,189 & 0,189 & 0,235
\end{tabular}

${ }^{\circledR}$ Copyright by Management of Aquatic Resources (MAQUARES) 
Berdasarkan data tersebut menunujukkan rata - rata kadar total fosfat tergolong baik. Rata - rata kadar total fosfat pada Waduk Jatibarang berkisar antara 0,1 - 0,2 ppm. Menurut Hutagalung dan Rozak (1997), kisaran nilai fosfat untuk pertumbuhan fitoplankton adalah $0,27-5,51 \mathrm{ppm}$. Sebaran kadar total fosfat ditunjukkan pada Gambar 11.

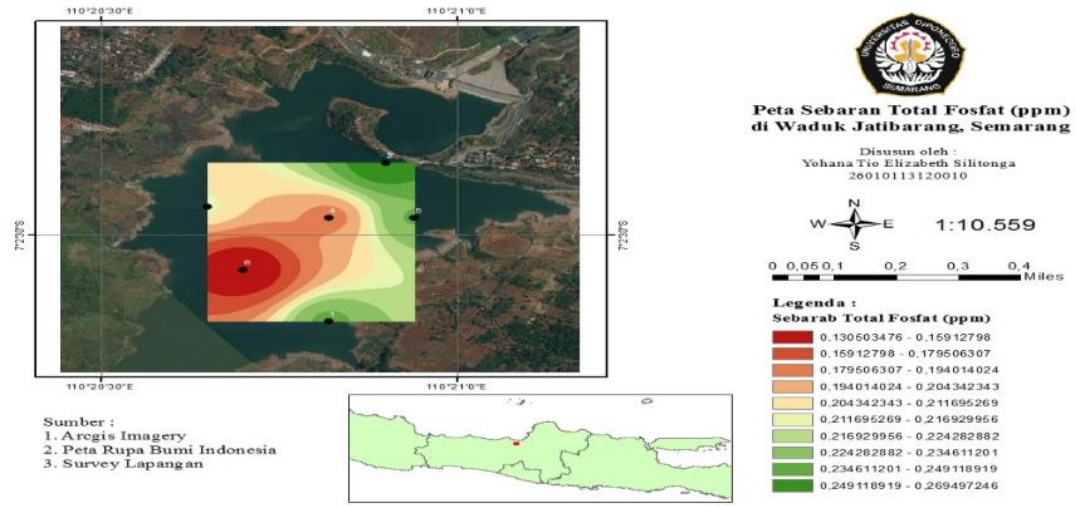

Gambar 11. Peta Sebaran Total Fosfat

Klorofil-a merupakan variabel utama yang menentukan kesuburan perairan. Hasil yang diperoleh selama penelitian ditunjukkan pada Tabel 3 .

Tabel 3. Hasil Pengukuran Klorofil-a

\begin{tabular}{cccc}
\hline \multirow{2}{*}{ Titik } & \multicolumn{2}{c}{ klorofil-a $\left(\mathrm{mg} / \mathrm{m}^{3}\right)$} & \multirow{2}{*}{ Rata-rata } \\
\cline { 2 - 3 } & 15 September 2017 & 27 September 2017 & 4,2955 \\
1 & 2,661 & 5,93 & 3,0255 \\
2 & 2,682 & 3,369 & 3,3205 \\
3 & 3,363 & 3,278 & 4,2645 \\
4 & 5,361 & 3,168 & 2,7215 \\
5 & 2,578 & 2,865 & 2,945 \\
6 & 2,986 & 2,904 & \\
\hline
\end{tabular}

Berdasarkan data tersebut menunujukkan rata - rata kadar klorofil-a tergolong eutrofik ringan. Rata rata kadar klorofil-a berkisar antara 2,7-4,2 mg/m³. Sebaran kadar klorofil-a ditunjukkan pada Gambar 12.

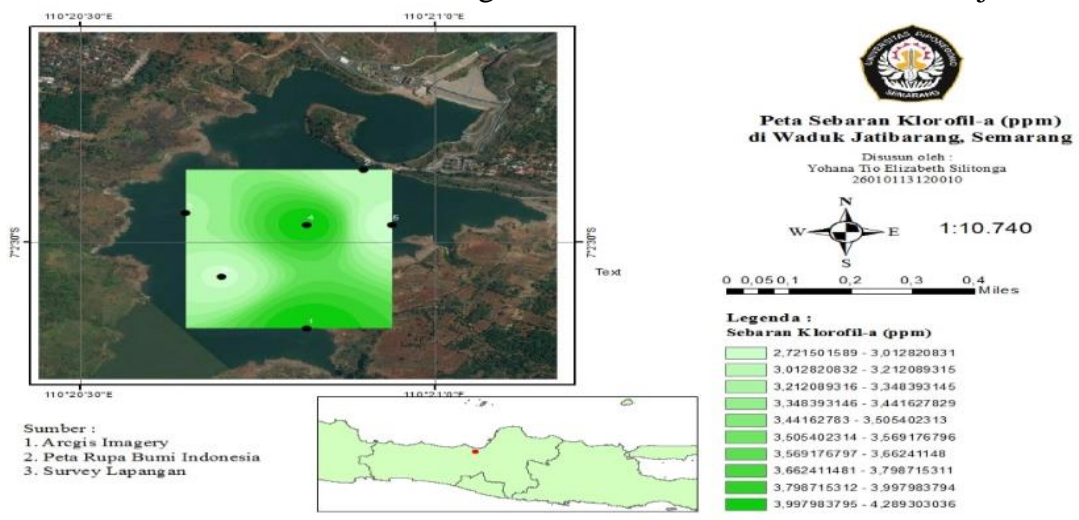

Gambar 12. Peta Sebaran Klorofil-a

\section{Perhitungan TSI Carlson} pada Tabel 4

Hasil perhitungan terhadap data kesuburan perairan berdasarkan TSI Carlson (1977) adalah terdapat Tabel 4. Hasil Perhitungan TSI

\begin{tabular}{cccccccc}
\hline \multirow{3}{*}{ Titik } & \multicolumn{3}{c}{ Parameter } & \multicolumn{3}{c}{ TSI } & Rata-rata \\
\cline { 2 - 6 } & Kecerahan & $\begin{array}{c}\text { Total fosfat } \\
(\mathrm{mg} / \mathrm{m} 3)\end{array}$ & $\begin{array}{c}\text { Klorofil-a } \\
(\mathrm{mg} / \mathrm{m} 3)\end{array}$ & Kecerahan & Total fosfat & Klorofil-a & TSI \\
\hline 1 & 0,3275 & 23,75 & 4,2955 & 76,085 & 49,826 & 44,898 & 56,936 \\
2 & 0,4375 & 26,95 & 3,0255 & 71,912 & 51,583 & 41,46 & 54,985 \\
3 & 0,4075 & 21,3 & 3,3205 & 72,936 & 48,256 & 42,373 & 54,521 \\
4 & 0,36 & 18,9 & 4,2645 & 74,721 & 46,532 & 44,827 & 55,36 \\
5 & 0,365 & 23,55 & 2,7215 & 74,523 & 49,704 & 40,421 & 54,883
\end{tabular}

${ }^{\circledR}$ Copyright by Management of Aquatic Resources (MAQUARES) 
Berdasarkan hasil perhitungan diatas menunjukkan rata - rata indeks TSI Carlson kesuburan perairan pada Waduk Jatibarang tergolong eutrofik ringan yang berkisar antara 52,57-56,93. Menurut Carlson (1977) dalam Shaleh et al (2014) bahwa kisaran nilai TSI pada 50 - 70 tergolong pada status eutrofik. Eutrofik ringan pada perairan masih dapat ditolerir oleh biota - biota yang ada diperairan.

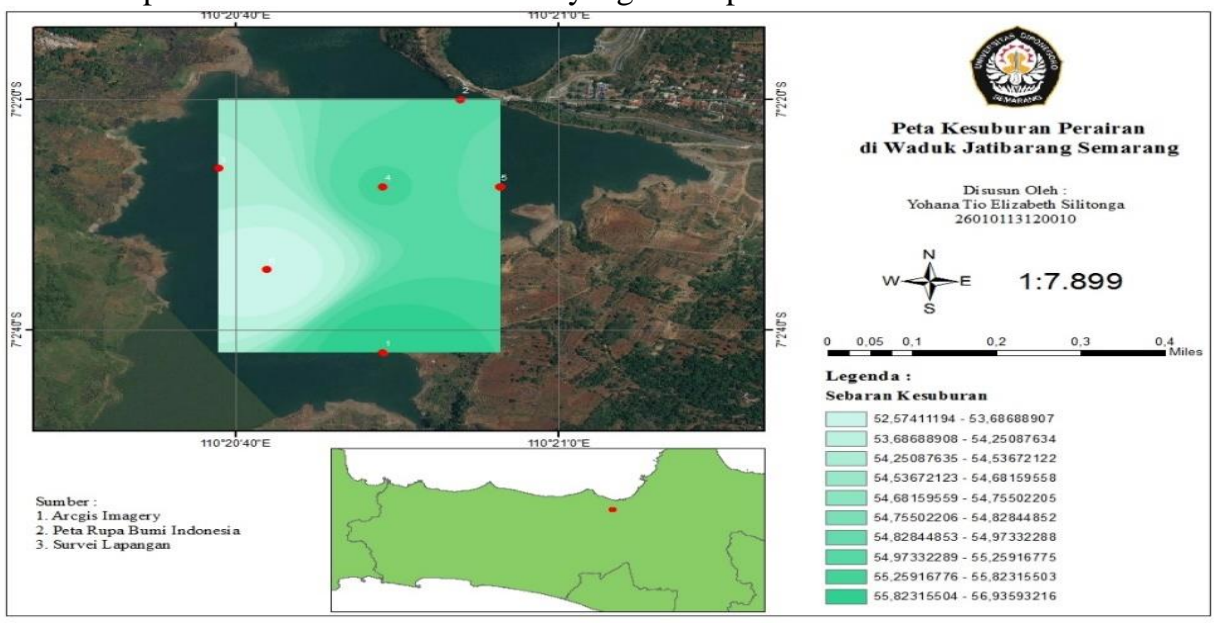

Gambar 13. Peta Kesuburan Perairan

\section{Pembahasan}

Temperatur merupakan salah satu parameter yang berperan penting dalam mengendalikan kondisi ekosistem perairan karena mencakup organisme - organisme perairan. Temperatur yang baik akan menjaga kesuburan suatu perairan dimana salah satu indikator kesuburan perairan adalah keberadaan fitoplankton. Temperatur yang baik bagi pertumbuhan fitoplankton menurut APHA (1989) dalam Hardiyanto et al., (2012) adalah berkisar antara $20-30{ }^{\circ} \mathrm{C}$. Berdasarkan hasil yang diperoleh dalam penelitian ini memiliki kisaran ratarata temperatur antara $30,5-31{ }^{\circ} \mathrm{C}$, kisaran ini masih tergolong dapat ditolerir oleh organisme perairan, baik ikan maupun fitoplankton.

Menurut Boyd (1990) dalam Hardiyanto et al., (2012) menungkapkan bahwa kisaran kecerahan yang baik untuk pertumbuhan plankton adalah $30-50 \mathrm{~cm}$. Berdasarkan hasil kecerahan yang diperoleh di Waduk Jatibarang memiliki kisaran rata - rata kecerahan antara 32,75 - 40,75 cm. Hal ini menunjukkan bahwa kondisi perairan diilihat dari dari kecerahan masih tergolong baik.

Arus pada perairan memiliki peran untuk membawa plankton atau menggerakkan plankton karena palnkton tidak memiliki alat penggerak untuk berpindah. Hal ini diperkuat oleh Davis (1951) dalam Harsono (2011) bahwa fitoplankton adalah organisme mikroskopis yang dapat melakukan fotosintesis dan tidak mempunyai daya gerak. Menurut Kawara (2002) dalam Harsono (2011) konsentrasi fitoplankton akan meningkat yaitu pada kecepatan arus yang kurang dari $10 \mathrm{~cm} / \mathrm{s}$ atau kurang dari $0,1 \mathrm{~m} / \mathrm{s}$. Berdasarkan hal tersebut menunujukkan bahwa kecepatan arus pada lokasi penelitian dalam kondisi yang baik bagi fitoplankton dengan kisaran rata - rata 0,017 - 0,14 m/s.

Kondisi perairan yang baik dilihat dari nilai $\mathrm{pH}$ perairan tersebut. Nilai $\mathrm{pH}$ pada suatu perairan akan berpengaruh pada kandungan bahan organik maupun anorganik yang akan mempengaruhi pertumbuhan organisme akuatik di perairan tersebut. Menurut Kep.MNLH (2004) bahwa nilai ambang batas pH yaitu 6,5 8,5. Berdasarkan hasil yang diperoleh menunjukkan kondisi $\mathrm{pH}$ pada perairan tergolong baik. Menurut Effendi (2003) dalam Syamiazi et al., (2015) bahwa nilai pH sangat mempengaruhi proses nitrifikasi yang akan menyebabkan $\mathrm{pH}$ kurang dari 6.

Tinggi rendah DO pada suatu perairan mempengaruhi parameter yang lain dan organisme akuatiknya. Kandungan DO pada suatu perairan berbanding terbalik dengan suhu. Menurut Menurut Kep.MNLH (2004) kisaran kandungan oksigen terlarut normal sesuai dengan baku mutu kualitas air untuk biota yang ditetapkan oleh melalui Kep. MNLH Nomor 51 (2004) yaitu > $5 \mathrm{mg} / \mathrm{l}$. Berdasarkan hasil yang diperoleh pada penelitian ini berkisar antara 4,56 - 6,96 mg/l. Hasil ini menunjukkan bahwa di beberapa titik perairan tersebut dalam kondisi tercemar ringan karena memiliki nilai $<5 \mathrm{mg} / \mathrm{l}$ namun masih dapat ditolerir oleh organisme akutaik di perairan tersebut.

Total Suspended Solid (TSS) dapat menunjukkan tingkat sedimentasi pada suatu perairan. Semakin tinggi tingkat sedimentasi suatu perairan maka menunjukkan perairan tersebut semakin keruh. Kekeruhan pada perairan yang disebabkan sedimentasi yang tinggi akan menghalangi fitoplankton dalam proses fotosintesis. Berdasarkan hasil penelitian ini diperoleh rata - rata kisaran konsentrasi TSS antara 60 - $130 \mathrm{mg} / \mathrm{l}$. Menurut PP No. 82 tahun 2001 mengenai baku mutu air kelas III (untuk perikanan) bahwa TSS memiliki nilai ambang batas maksimal $400 \mathrm{mg} / \mathrm{L}$, dalam hal ini TSS perairan Waduk Jatibarang Semarang tergolong normal karena nilai TSS berada dibawah nilai ambang batas. 
Total Dissolved Solid merupakan total zat yang terlarut yang dapat melewati kertas saring. Tingkat konsentrasi TDS pada suatu perairan memiliki baku mutu tertentu yang menunjukkan bahwa perairan tersebut masih dalam kondisi baik. Menurut PP No.82. 2001 kriteria air yang sesuai baku mutu adalah <1000 mg/l yang artinya jumlah residu terlarut dalam perairan masih memenuhi standar baku mutu air. Berdasarkan hasil penelitian diperoleh kisaran rata - rata TDS antara 245 - $360 \mathrm{mg} / \mathrm{l}$ yang berarti kualitas perairan dilihat dari konsentrasi TDS.

Menurut Mulyadi (1999) nitrat merupakan senyawa yang penting dalam produktivitas primer yaitu sebagai unsur yang dimanfaatkan oleh fitoplankton dan dibutuhkan dalam proses fotosintesis. Nitrat pada suatu perairan memiliki ambang batas tertentu yang dapat ditolerir oleh organisme akuatik. Menurut Basmi (2000), pertumbuhan optimal fitoplankton jika kandungan nitrat di perairan 3,9-15,5 ppm. Berdasarkan hasil yang telah diperoleh selama penelitian, kisaran rata - rata kandungan nitrat dilokasi penelitian berkisar antara 0,6415 1,106 ppm. Nilai ini menunjukkan perairan masih dalam kondisi baik untuk ekosistem perairan tersebut.

Kandungan fosfat pada suatu perairan merupakan acuan untuk menilai kesuburan perairan tersebt. Fosfat yang terdapat didalam perairan pada umumnya berasal dari limbah rumah tangga. Menurut Effendi (2003) bahwa selain berasal dari hasil pelapukan batuan, fosfat dapat berasal dari limbah rumah tangga, limbah industri, dan limbah pertanian. Berdasarkan hasil yang diperoleh dari lokasi penelitian diperoleh hasil kisaran rata - rata total fosfat antara 0,1305 - 0,2695 ppm. Menurut Hutagalung dan Rozak (1997), kisaran nilai fosfat untuk pertumbuhan fitoplankton adalah 0,27 - 5,51 ppm. Hal ini menunujukkan bahwa total fosfat di Waduk Jatibarang masi dibawah batas optimum untuk pertumbuhan fitoplankton.

Berdasarkan hasil perhitungan dalam penentuan indeks TSI pada masing - masing parameter diperoleh kisaran rata - rata antara 52,574 - 55,36. Nilai indeks TSI ini menunjukkan status kesuburan perairan pada waduk Jatibarang tergolong pada eutrofik ringan. Menurut Carlson (1977) bahwa kisaran nilai TSI pada 50 - 70 tergolong pada status eutrofik. Eutrofik ringan pada perairan masih dapat ditolerir oleh biota - biota yang ada diperairan. Kondisi perairan di waduk Jatibarang masih dapat tergolong baik didukung dengan parameter parameter lainnya yang diukur selama penelitian menunjukkan kondisi yang baik dan masih dapat ditolerir oleh biota - biota perairan. Kandungan DO yang berkisar antara 4,8 - 6,96 mg/l menunjukkan kondisi perairan yang masih tergolong baik. Kandungan DO yang masi batas wajar dapat disebabkan oleh lokasi Waduk Jatibarang berada pada lokasi yang masih banyak vegetasi. Dapat dilihat kembali pada peta tata guna lahan yang menunjukkan bahwa sebagian besar lahan ditutupi oleh vegetasi baik oleh rumput maupun kebun yang berada sangat dengan perairan. Kondisi pada perairan ini juga didukung oleh penataan lahan pada lokasi penelitian yang masih baik dan belum dipadati oleh pemukiman warga yang dapat menyumbang limbah rumah tangga yang dapat mempengaruhi kesuburan perairan.

\section{KESIMPULAN}

Kondisi penataan lahan pada bagian hulu Waduk Jatibarang tergolong masih baik. Sebagian besar lahan di bagian hulu Waduk Jatibarang terdiri dari $50 \%$ vegetasi, 20\%, pemukiman, 25\% persawahan dan $5 \%$ tegalan. Vegetasi yang dominan mempengaruhi kondisi kesuburan perairan di Waduk Jatibarang. Indeks TSI Carlson Waduk Jatibarang berkisar antara 52,57 - 56,93 yang menunujukkan status kesuburan perairan eutrofik ringan

\section{UCAPAN TERIMAKASIH}

Penulis mengucapkan terimakasih kepada Ir. Siti Rudiyanti, M.Si dan Arif Rahman, S.Pi, M.Si selaku tim penguji yang telah membantu dalam pembuatan jurnal ini.

\section{DAFTAR PUSTAKA}

Basmi, H.J. 2000. Planktonologi: plankton sebagai indikator kualitas perairan. Fakultas Perikanan dan Ilmu Kelautan, IPB. 8(2): 77-88

Carlson RE. 1977. A trophic state index for lakes. Limnology and Oceanography. 22(2): 361369.

Effendi. 2003. Telaah Kualitas Air. Kanisius, Yogyakarta, 257 hlm.

Hardiyanto, Rizky, Henhen Suherman, Rusky Intan Pratama. 2012. Kajian Produktivitas Primer Fitoplankton di Waduk Saguling, Desa Bongas Dalam Kaitannya Dengan Kegiatan Perikanan. Jurnal Perikanan dan Kelautan. 3 (4): $51-59$

Harsono, Eko. 2011. Kajian Hubungan Antara Fitoplankton dengan Kecepatan Arus Air Akibat Operasi Waduk Jatiluhur. Jurnal Biologi Indonesia. 7 (1): 99 - 120

Hutagalung, H. P., Rozak, A. 1997. Metode analisis air laut, sedimen dan biota laut. LIPI. Buku 2, Jakarta. 223 p.

[KLH] Kementerian Lingkungan Hidup Republik Indonesia .2004. Baku mutu air laut untuk biota laut. Keputusan Menteri Negara Lingkungan Hidup No.51 Tahun 2004 Tentang Baku Mutu Air Laut. KLH. Jakarta

Mulyadi. A. 1999. Pertumbuhan dan Daya Serap Nutrien dari Mikroalgae yang Terpelihara pada Limbah Domestik. Jurnal natur Indonesia (II). Fakultas Perikanan dan Ilmu Kelautan Riau. Riau

Paramitha, Amanda. 2014. Studi Klorofil-a di Kawasan Perairan Belawan Sumatera Utara. (Skipsi). Medan: Manajemen Sumberdaya Perairan, Fakultas Pertanian, Universitas Sumatera Utara

\footnotetext{
${ }^{\circ}$ Copyright by Management of Aquatic Resources (MAQUARES)
} 
Poppo, A., Mahendra, M.S., dan Sundra, K.I. 2007. Studi Kualitas Perairan Pantai di Kawasan Industri Perikanan. Dinas Pengambengan.Kecamatan Negara. Kabupaten Jembrana. Jurnal. Unud. Bali.

Shaleh, F. R., Kadarwan S. dan Sigid H. 2014. Kualitas Air dan Status Kesuburan Perairan Waduk Sempor, Kebumen. Jurnal Ilmu Pertanian Indonesia. 19 (3): 169 - 173

Susanti, I. T., Setia B. S. dan Sudarno. 2012. Status Trofik Waduk Manggar Kota Balikpapan dan Strategi Pengelolaannya. Jurnal Presipitasi. 9 (2): $72-78$

Syamiazi, Fauzi Dwi Noor, Saifullah, Forcep Rio Indaryanto. 2015. Kualitas Air di Waduk Nadra Kerenceng Kota Cilegon Provinsi Banten. Jurnal Akuatik. VI (2): 161 - 169

Widayanti, Rina. 2010. Formulasi Model Pengaruh Perubahan Tata Guna Lahan Terhadap Angkatan Kota di Kota Depok 